\title{
Modulatory effect of $17 \beta$-estradiol on myeloid cell infiltration into the male rat brain after ischemic stroke
}

Scheld M. ${ }^{1,2}$, Heymann F. ${ }^{3}$, Zhao W. ${ }^{1}$, Tohidnezhad M. ${ }^{4}$, Clarner T. ${ }^{1}$, Beyer C. ${ }^{1}$, Zendedel A. ${ }^{1, C A}$

${ }^{1}$ Dr. rer. nat. Miriam Scheld, University Clinic, Institute of Neuroanatomy, RWTH Aachen University, mscheld@ukaachen.de and 2Anatomy and Cell Biology, University of Augsburg, miriam.scheld@med.uni-augsburg.de

3 Dr. rer. nat. Felix Heymann, Department of Hepatology \& Gastroenterology, Charité Universitätsmedizin Berlin

${ }^{1}$ M. Sc. Weiyi Zhao, University Clinic, Institute of Neuroanatomy, RWTH Aachen University

${ }^{4}$ Dr. rer. nat. Mersedeh Tohidnezhad, University Clinic, Institute of Anatomy and Cell Biology, RWTH Aachen University

${ }^{1}$ Priv.-Doz. Dr. rer. nat. Tim Clarner, University Clinic, Institute of Neuroanatomy, RWTH Aachen University

${ }^{1}$ Univ.-Prof. Dr. hum. biol. Cordian Beyer, University Clinic, Institute of Neuroanatomy, RWTH Aachen University

1, CA Dr. med. Adib Zendedel, University Clinic, Institute of Neuroanatomy, RWTH Aachen University

\section{Highlights}

- Estradiol substitution significantly reduced the cortical infarct area and improved neurological scoring in the tMCAO model.

- $\quad$ TMCAO increased CD45 ${ }^{+}$and CD45+CD11 b+CD11 ${ }^{+}$cell percentages.

- Estradiol prevented the increase in $\mathrm{CD}^{2} 5^{+}$and $\mathrm{CD} 45^{+} \mathrm{CD} 11 \mathrm{~b}^{+} \mathrm{CD} 11 \mathrm{c}^{+}$cell numbers.

- Estradiol selectively regulated neuroinflammatory responses mediated by microglia- or infiltrated macrophage signaling. 


\section{Abstract}

Ischemic stroke is the leading cause of human disability and mortality in the world. Neuroinflammation is the main pathological event following ischemia which contributes to secondary brain tissue damage which is driven by infiltration of circulating immune cells such as macrophages. Because of neuroprotective properties against ischemic brain damage, estrogens have the potential to become of therapeutic interest. However, the exact mechanisms of neuroprotection and signaling pathways is not completely understood. In the current study, 12week-old male Wistar rats underwent an experimental ischemia by occluding the middle cerebral artery transiently (tMCAO) for $1 \mathrm{~h}$. Male rats subjected to tMCAO were randomly assigned to receive $17 \beta$-estradiol or vehicle treatment. The animals were sacrificed $72 \mathrm{~h}$ post tMCAO, transcardially perfused and the brains were proceeded either for TTC staining and gene analysis or for flow cytometry (CD45, CD11b, CD11c, CD40). We found that 17 $\beta$-estradiol substitution significantly reduced the cortical infarct which was paralleled by an improved Garcia test scoring. Flow cytometry revealed that $C D 45^{+}$cells as well as $C D 45^{+} \mathrm{CD} 11 \mathrm{~b}^{+} \mathrm{CD} 11 \mathrm{c}^{+}$cells were massively increased in TMCAO animals and numbers were nearly restored to sham levels after $17 \beta$-estradiol treatment. Gene expression analysis showed a reperfusion time-dependent upregulation of the markers CD45, CD11b and the activation marker CD40. The reduction in gene expression after 72 hours of reperfusion and simultaneous $17 \beta$-estradiol substitution did not reach statistical significance. These data indicate that $17 \beta$-estradiol alleviated the cerebral ischemia-reperfusion injury and selectively suppressed the activation of the neuroinflammatory cascade via reduction of the number of activated microglia or infiltrated monocyte-derived macrophages in brain.

\section{Introduction}

Estrogens are the primary female sex hormones that are responsible for female reproduction and act through binding to nuclear estrogen receptors ( $n E R$ ) which modulate the expression of many genes such as lipocalin-2, angiotensin or progesterone receptor [1, 2]. Besides, estrogens can bind and activate membrane-bound ERs (mER) which are accountable for many so-called nongenomic estrogen effects such as sexual behavior, pain perception or the prevention of vascular injury [3-5]. In addition to reproductive functions, estrogens also regulate neuronal differentiation and brain function [6]. There is growing evidence that estrogens can modulate a number of peripheral immune cell functions as well as neuro-immune responses in the central nervous system (CNS) [6, 7]. The pathophysiology and outcome after neurological injuries often reveals a clear-cut gender difference. This has led to the assumption that female sex steroids may contribute 
to the disease course and severity in some way or another [8]. A number of experimental studies in the past decade have now proven that estrogens act anti-inflammatory and neuroprotective in many models of brain injury, including stroke and Alzheimer's disease [9, 10]. One of the first studies showing that estrogens have a protective effect on ischemic stroke outcome was conducted by Simpkins and colleagues in 1997 [11]. In this study, various 17ß-estradiol (in the following $17 \beta$-estradiol is stated as "estradiol") concentrations were administered to female ovariectomized rats after MCA occlusion which led to a decrease of mortality and a reduced ischemic area. In the sequel, many studies have proven the neuroprotective effects of estrogens mainly in disease-related animal models [12-14]. Using a transient ischemic stroke rat model (transient middle cerebral artery occlusion, tMCAO), a spinal cord injury rat model, an amyotrophic lateral sclerosis mouse model $\left(\mathrm{SOD} 1^{\mathrm{G} 93 \mathrm{~A}}\right)$ and a multiple sclerosis mouse model, we have demonstrated in a series of studies that estradiol exerts a neuroprotective role, thereby reducing tissue damage and neuronal death [15-17]. All the projects have in common that estradiol rapidly within hours dampens neuroinflammation and microgliosis. In vitro studies further revealed that estradiol modulates the activation of microglia and promotes the differentiation towards a more phagocytic and rather protective M2 phenotype [18].

Ischemic stroke is the fourth leading cause of death and the leading cause of neurological disability worldwide. Generally, ischemic conditions in the brain are generated by a sudden occlusion of a cerebral artery by a local thrombus or embolus [19]. Ischemia leads to an insufficient blood and oxygen supply resulting in neuronal death along with later occurring reperfusion injuries [20]. The mechanisms of neuronal cell death after cerebral ischemia have not been fully understood but both necrotic and apoptotic cell death as well as pyroptosis are present in the infarct area. In ischemic stroke, two different immune reactions are observed. Central responses mediated through the activation of resident microglial cells, and peripheral responses due to an infiltration of blood-derived leukocytes into the brain. Both mechanisms, although to differing degrees and with different complex time processes, result in post-stroke neuroinflammation [21]. Neuroinflammatory responses in turn induce the release of reactive oxygen species and promote immune-derived mechanisms associated with cytotoxicity and brain damage [22]. There exist a battery of possible mechanisms by which estrogens may achieve neuroprotection such as affecting cerebral blood flow, nitric oxide formation, leukocyte adhesion, anti-oxidative mechanisms, glutamate excitotoxicity and the activation state of local glial cells [8]. Microglia cells are the resident immune cells of the CNS and react quickly to ischemia by becoming reactive and producing pro- and anti-inflammatory cytokines and chemokines that initiate and perpetuate inflammatory processes [10]. Such regulatory effects of estrogens on the activation status of 
microglia as well as monocytes-derived macrophages (MDMs) under inflammatory conditions have been previously described [23-25]. By binding to nuclear estrogen receptors, microglia and MDMs are shifted from their activated pro-inflammatory state to an anti-inflammatory cell type [24, 26, 27].

In this study, we aimed at identifying changes in the proportion/population of microglia and MDMs using the IMCAO male rat model after $72 \mathrm{~h}$ of reperfusion and concomitant estradiol substitution. For that, we developed an ex vivo flow cytometry technique that allows to extract living tissue from the infarcted cerebral cortex and subdivide the population of microglia and MDMs along their immunological surface pattern. Finally, quantitative studies should provide further information about the effectiveness of estradiol to reduce the pro-inflammatory phenotype of microglia and MDMs. Furthermore, microglia and MDM activation markers were investigated by a multiplex immunoassay at the protein level and for mRNA expression levels using RT-qPCR.

\section{Materials and Methods}

\section{Animals and surgery}

All experimental procedures and animal care were approved by the review board for the care of animal subjects of the district government (LANUV, Germany, AZ: 84-02.04.2013.A212) and are reported in accordance with the ARRIVE guidelines. Male Wistar rats (12-14 weeks old, male, 260-300 g, Janvier) were maintained in a pathogen-free environment with access to water and food ad libitum in a $12 \mathrm{~h}$ light/dark cycle and at controlled temperature and humidity $\left(23 \pm 2^{\circ} \mathrm{C} ; 55\right.$ $\pm 10 \%$ humidity). All operations were performed between 8 and 11 a.m. Prior to surgery, rats were randomly assigned to receive sham or tMCAO procedure as well as $17 \beta$-estradiol or vehicle treatment. In order to prevent dehydration, animals were subcutaneously injected with $300 \mu \mathrm{L}$ of $0.9 \% \mathrm{NaCl}$ (08779253, B. Braun); as an additional pain therapy, $0.01 \mathrm{mg} / \mathrm{kg}$ buprenorphine (Temgesic ${ }^{\circledR}$, Indivior Europe Ltd.) was subcutaneously applied. Transient focal cerebral ischemia was induced via intraluminal occlusion of the left middle cerebral artery (MCA) for one hour as previously described [28]. Briefly, rats were anesthetized with $2 \%$ isoflurane (PZN-9714675, Abbott) and a laser Doppler system (Moor Instruments VMS-LDF2) was used to monitor regional cerebral blood flow ( $\mathrm{rCBF}$ ) on both sides during surgery. After exposure of the left common carotid artery (CCA), internal carotid artery (ICA) and external carotid artery (ECA), the vagal nerve was carefully dissected from the ICA. Through the distal CCA a $0.1 \%$ poly-L-lysine coated 3-0 monofilament MCAO suture (404156PK5Re, Doccol) of $5 \mathrm{~cm}$ length was introduced into the ICA and advanced until an immediate drop in baseline rCBF occurred. During the entire surgical procedure, the body temperature was maintained at $37-37.5^{\circ} \mathrm{C}$ with a heating pad (Fine Science 
Tools). One hour after the occlusion, brain reperfusion was restored by removal of the filament and the neck incision was closed aseptically. Sham operated animals served as a control and were subjected to a similar surgical procedure under anesthesia (neck incision and separation of the bifurcation) but without occlusion of the MCA. After the surgery, animals were returned to their heated cages individually. As a follow-up pain management, buprenorphine was applied every 8$12 \mathrm{~h}$ subcutaneously. The animals were monitored daily after surgery and finalized by transcardial perfusion as published previously [29]. 17ß-estradiol (E1024, Sigma Aldrich) was dissolved in ethanol (9065.4, Carl Roth) and injected subcutaneously as neck depots (500 $\mu \mathrm{L}, 25 \mu \mathrm{g} / \mathrm{kg}$ body weight) immediately after withdrawal of the catheter and each $12 \mathrm{~h}$ later for 6 times in total. Ethanol served as vehicle and was injected likewise. For gene expression analysis, brain samples were obtained from ischemic animals at 1, 3, 6, 12, 24 and $72 \mathrm{~h}$ post-reperfusion, for protein analysis at 24 and $72 \mathrm{~h}$ post-reperfusion and for immunohistochemistry, TTC staining and flow cytometry at $72 \mathrm{~h}$ post-reperfusion.

\section{Behavioural testing}

To investigate the effect of hormone substitutions on neurological behaviour after stroke, rats underwent a Garcia test scoring with some minor modifications as follows [30, 31]:

1. Spontaneous activity was analysed for $3 \mathrm{~min}$ by placing the rats in the middle of the cage (scores: 3 = moving around, exploring the environment, and approaching at least three walls of the cage; 2 = slightly affected, moving around in the cage but not approaching the walls, nonetheless eventually rising to at least one upper rim of the cage; 1 = severely affected, not rising up at all and barely moving in the cage; $0=$ not moving).

2. Forepaw outstretching: rats were fixed at the tail, and the symmetry of the outstretching of both forelimbs was figured out (scores: 3 = both forelimbs outstretched symmetrically; 2 = right side moves and outstretches less than left side; 1 = right side moves slightly; $0=$ right forelimb not moving).

3. To assess the climbing ability, rats were placed on the wall of a wire cage (scores: $3=$ climbing easily and gripping the wire tightly; 2 = right side impaired when climbing or not gripping as tightly as the left side; 1 = failing to climb or tending to circle instead of climbing).

4. To check the body proprioception, rats were touched with a blunt stick on each side of the body, and the reaction to the stimulus was evaluated (scores: $3=$ reacts by turning head and being equally startled by the stimulus on both sides; 2 = reacts slowly to stimulus on right side; $1=$ not responding to stimulus placed on the right side). 
5. Spontaneous walking activity (scores: $3=$ walking straight ahead; $2=$ right circling; $1=$ tending to walk toward the right side; $0=$ not moving).

6. Sensory function was tested by brushing the vibrissae (scores: $3=$ turns head to the stimulus side; 2 = reacts slowly to stimulus on right side; 1 = no response to stimulus on right side).

\section{TTC staining and real-time quantitative PCR}

After ischemia, rats were transcardially perfused with $0.9 \% \mathrm{NaCl}$ to remove blood from the brain vasculature. Brains were rapidly removed and cut into $2 \mathrm{~mm}$ coronal sections. Coronal sections were incubated with $2 \%$ 2,3,5-triphenyltetrazolium chloride (TTC, T8877, Sigma) diluted in $0.9 \%$ $\mathrm{NaCl}$ for $5 \mathrm{~min}$ at $37^{\circ} \mathrm{C}$. Coronal slices were arranged in a frontal to occipital order, and digital photographs of all stained slices were taken using a digital camera. Infarct areas were evaluated in a blinded manner using the open access morphometric software ImageJ 1.41. Total infarct volumes were calculated by adding the mean-area of each section and multiplied by $2 \mathrm{~mm}$ (thickness of the sections). Oedema correction of the infarct volume was performed using following paradigm: volume correction (infarct volume $\mathrm{x}$ contralateral volume/ipsilateral volume). Infarct size was quantified from images by assessing damaged tissue area in the left hemisphere via ImageJ software and then normalized to the total area of contralateral hemisphere.

Gene expression and protein analysis were performed with tissues corresponding to the periinfarct area with 5 animals per group. The peri-infarct area can easily be observed based on the intensity of brick-red colour after TTC-staining. The infarct tissue appears bright white, the living tissue in light red and the peri-infarct in mild white as well as in colour transitions. After definition of the peri-infarct area, the biopsy was performed using a disposal biopsy punch, $4.0 \mathrm{~mm}$ from the frontal-parietal cortex (Bregma 1 to 3.60) and a stereomicroscope.

Total RNA was extracted using peqGold RNA TriFast (30-2020, Peqlab) as previously described [32]. RNA concentration and purity were measured with the NanoDrop 1000 device (Peqlab). cDNA synthesis was performed using Moloney murine leukemia virus reverse transcriptase (MMLV) reserve transcription kit (28025-021, Thermo Fisher Scientific Inc.) and random hexanucleotide primers (48190-011, Invitrogen) adjusting the concentration to $1 \mu \mathrm{g} / \mathrm{mL}$ of total RNA. RT-qPCR analysis was performed using the MylQ detection system (Biorad). Relative quantification was calculated by the $\Delta \Delta \mathrm{Ct}$-method using the qbase+ software (Biogazelle). Data were expressed as relative amount of the target gene to the amount of the reference gene Cyclophilin A. The values of sham animals were set to $100 \%$. Data of interest are given as relative expression. A list of used primers and analyzed genes is given in table 1. 


\section{Multiplex immunoassay}

After transcardial perfusion with $0.9 \% \mathrm{NaCl}$, the dissected peri-infarct areas were lysed with ProcartaPlex cell lysis buffer (EPX-99999-000, Invitrogen) and homogenized with microbeads for $1 \mathrm{~min}$. After centrifugation at $16,000 \mathrm{G}$ for $10 \mathrm{~min}$, total protein concentration of the supernatant was measured by BCA assay. Cytokine and chemokine 22-ProcartaPlex immunoassay (IL-1 $\alpha$, IL$1 \beta$, IL-2, IL-4, IL-5, IL-6, IL-10, IL-12p70, IL-13, IL-17A, G-CSF, GM-CSF, IFN $\gamma$, TNF $\alpha$, CXCL1, CXCL2, CXCL10, CCL2, CCL3, CCL5, CCL7 and CCL11) was performed according to manufacturer's recommendations with provided assay solutions (EPX220-30122-901, Thermo Fisher Scientific Inc.). Brief, magnetic beads were transferred into each well. After a washing step with a hand-held magnetic plate washer and wash buffer, universal assay buffer was added to each well and standards as well as samples $(2.5 \mu \mathrm{g} / \mu \mathrm{L}$ of total protein) were added to the appropriate wells. After an overnight-incubation and washing steps, the detection antibody and streptavidin-PE were incubated for $30 \mathrm{~min}$ one after another with in-between washing steps. The samples were measured in reading buffer with Luminex Magpix Systems and Luminex xPonent Software (Merck Millipore).

\section{Immunohistochemical staining}

Brains of 5 animals per group were removed after transcardial perfusion, embedded in paraffin and cut into $5 \mu \mathrm{m}$ thick slides. After rehydration, antigens were unmasked by heating for $10 \mathrm{~min}$ in Tris/EDTA buffer (pH 9.0). Unspecific binding was saturated with normal serum in PBS (S-1000, Vector Labs), and anti-rat IBA-1 (ab107159, Abcam, 1:2,500) was incubated overnight at $4{ }^{\circ} \mathrm{C}$ to detect microglia and MDMs. The next day, endogenous peroxidases were blocked with $\mathrm{H}_{2} \mathrm{O}_{2}$, and a biotinylated secondary antibody rabbit-anti-goat IgG (ab6740-1, Abcam, 1:50) was incubated. A peroxidase-coupled avidin-biotin complex (PK-6100, Vector Laboratories) and the substrate diaminobenzidine (K3468, DAKO) were incubated one after another before staining the cell nuclei with haematoxylin (517-28-2, Merck Millipore). After dehydration, slides were mounted in DePeX (18243, Serva). Images were acquired with a Leica DMI 6000 B microscope and LAS X software. Quantification of Iba-1 positive cell counts was performed by manually counting the number of positive signals in the peri-infarct area of the brain. For each animal, a total of eight slices were analyzed with a distance of $150 \mu \mathrm{m}$ in between. Counting was performed using a Nikon Eclipse 55i (Nikon) and a 20x objective. Cell numbers are expressed as cells per $\mathrm{mm}^{2}$. To determine the area with ImageJ, the peri-infarct area was outlined and measured after setting the length of the scale bar. 


\section{Flow cytometry}

After transcardial perfusion with $0.9 \% \mathrm{NaCl}$, brains of at least 6 animals per group were removed, and both hemispheres without brainstem or cerebellum mechanically disrupted in a HBSS-based buffer solution (24020, Thermo Fisher Scientific Inc.). Homogenized ipsilateral and contralateral hemispheres were filtered separately through a $70 \mu \mathrm{m}$ cell strainer to obtain a single cell suspension. After centrifugation at $220 \mathrm{rcf}$, the cell suspension was re-suspended in a $22 \%$ percoll (P1644, Sigma Aldrich) gradient buffer and overlaid with ice cold DPBS (14190, Thermo Fisher Scientific Inc.). The gradient was conducted at $950 \mathrm{rcf}$ with a reduced acceleration and no brakes. Unspecific binding was saturated with CD32 antibody (1:200) before the staining procedure. FVD560 staining served for the exclusion of dead cells, see table 2 for full antibody descriptions. The stained single cell suspension was measured with a BD FACS Fortessa and analyzed by the forward scatter (FSC), forward scatter width (FSC-W), sideward scatter (SSC), marker expression and mean fluorescence intensity (MFI) with the FlowJo v10 software. The gating and analysis were performed by two independent researchers.

\section{Statistical analysis}

JMP10 and GraphPad Prism 5 software were used for statistical analysis. Data are presented as arithmetic means \pm SEM. Bartlett test was performed to test for equal variances. Data were transformed via Boxcox for homoscedasticity and indicated if applicable. Normal distribution was tested with Shapiro-Wilk test. One-way ANOVA followed by Tukey's post hoc test for multiple comparisons or Student's t-test were used for parametric data. Non-parametric data were analyzed with Kruskal-Wallis test followed by the Dunn's multiple comparison or Mann-Whitney test. $p<0.05$ was considered statistically significant and the following symbols were used to indicate the level of significance: ${ }^{*} p<0.05,{ }^{* *} p<0.005,{ }^{* * *} p<0.001$. "ns" indicates not significant.

\section{Results}

\section{Estradiol reduces the infarct volume after tMCAO}

To assess the post-ischemic neurological deficits, Garcia tests with some minor modifications were performed [30]. Sham animals always reached an average score of $100 \%$, whereas tMCAO animals had a significant lower score with an average of $48 \%$ of points indicating severe motor deficits (figure $1 \mathrm{~A}$ ). The application of estradiol preserved the scoring rates to $82 \%$ which shows a significant improvement compared to vehicle-treated tMCAO animals. In accordance, TTC staining revealed that estradiol substitution significantly reduced the infarct area compared to vehicle-treated tMCAO animals (120 $\mathrm{mm}^{3}$ vs. $227 \mathrm{~mm}^{3}$; figure $1 \mathrm{~B}$ and C). Immunohistochemical staining of IBA-1 demonstrates that the number of microglia/macrophages is increased after tMCAO and that estradiol reduces the number of IBA-1+ cells (figure $1 \mathrm{D}, \mathrm{E}$ ), albeit the overall 
count of $\mathrm{IBA}-1^{+}$cells remained elevated in comparison to healthy controls and the cellular morphology also reflected at least in part the macrophages visible in the TMCAO group. These findings confirm previous data about the protective function of estradiol with respect to Garcia scoring, infarct volume and microgliosis [10, 11, 31, 33].

\section{Estradiol reduces $\mathrm{CD}^{4} 5^{+}$and $\mathrm{CD} 45^{+} \mathrm{CD} 11 \mathrm{~b}^{+} \mathrm{CD} 11 \mathrm{c}^{+}$cell numbers}

Since it has been reported that estradiol has strong anti-inflammatory effects, the number of resident as well as infiltrated immune cells in the ischemic hemisphere were investigated by flow cytometry analysis. CD45 is a marker for all leukocytes as well as microglia, CD11b and CD11c are markers for microglia and MDMs, and CD40 is a marker for activated microglia and MDMs. In a first step, we found a significant increase of CD45+ cells from $5 \%$ to $49 \%$ after $72 \mathrm{~h}$ of tMCAO (figure $2 \mathrm{~A}, \mathrm{~B}$ ). This massive increase of $\mathrm{CD} 45^{+}$cells also becomes apparent in representative gating plots in figure $2 \mathrm{~B}$. After estradiol substitution, $\mathrm{CD} 45^{+}$proportions decreased significantly to $18 \%$ but did not completely lapse to basal sham levels.

To determine the concentration of microglia and MDM populations, CD11 $\mathrm{b}^{+} \mathrm{CD} 11 \mathrm{c}^{+}$cells and $\mathrm{CD} 11 \mathrm{~b}^{+} \mathrm{CD} 40^{+}$cells were gated. The analysis revealed that $\mathrm{MCAO}$ resulted in a significant expansion of the total number of $C D 11 b^{+} C D 11 c^{+}$(from $3.5 \%$ to $11.5 \%$ ) and of CD11 $b^{+} C D 40^{+}$ cells (from $6 \%$ to $22 \%$ ) at $72 \mathrm{~h} \mathrm{tMCAO} \mathrm{compared} \mathrm{to} \mathrm{sham-operated} \mathrm{animals} \mathrm{(figures} 2 \mathrm{C}, \mathrm{E}$ ). The $\mathrm{CD} 11 \mathrm{~b}^{+} \mathrm{CD} 11 \mathrm{c}^{+}$cell proportion was significantly reduced to $4.5 \%$ after estradiol substitution of tMCAO animals and the CD11 $\mathrm{b}^{+} \mathrm{CD} 40^{+}$gating showed a strong trend towards a lower proportion of those cells in estradiol-treated animals compared to vehicle-treated animals. The different expression patterns of CD11b, CD11c and CD40 in vehicle- and estradiol-treated animals can also be observed in the representative plots in figure $2 \mathrm{D}, \mathrm{F}$.

In the next step, we quantified the surface expression levels of CD40 by mean intensity fluorescence measurement following surface staining and flow cytometry analysis. CD40 is a surface activation marker associated with immunogenic activation of dendritic cells but also found in subsets of macrophages during the course of inflammation. CD40-MFI of CD45 ${ }^{+}$CD $11 b^{+} C D 11 c^{+}$ cells was strongly increased after $\mathrm{IMCAO}$, which showed a trend towards a decrease again when substituting with estradiol (figure 3 A).

\section{Gene expression of microglia/monocyte markers}

To confirm our flow cytometry data, gene expression levels of selected markers were analyzed using RT-qPCR at different time points after tMCAO and in sham animals. After $6 \mathrm{~h}$ of reperfusion, gene expression of CD45, CD11b and CD40 were significantly induced (figure 3 B - D). Furthermore, they showed a further increase in gene expression up to $72 \mathrm{~h}$ of reperfusion. 
Estradiol substitution significantly decreased the gene expression after $72 \mathrm{~h}$ of reperfusion of all four markers.

\section{Protein concentrations of inflammatory markers}

To evaluate the inflammatory profile of the ischemic brain tissue with and without estradiol substitution, we also measured brain levels of 22 classical inflammatory cytokines involved in postischemic brain injury using a 22-plex assay. Among these pro-inflammatory chemokines, IFN $\gamma$, CXCL10, CCL2 and CCL7 showed a significantly increased protein concentration in the tMCAO group compared to sham operated animals (figure 4 A - D). Estradiol substitution caused a strong, decrease of the protein concentrations of those markers.

\section{Discussion}

Ischemic stroke accounts for approximately $80 \%$ of all strokes, yet there are very few therapeutic approaches available to cure this disease. Those that exist, such as thrombolytic tissue plasminogen activator, are limited by a narrow therapeutic window [34]. Ischemic stroke usually results from a thrombotic or embolic occlusion of a major cerebral artery, most often an occlusion of the MCA. Therefore, related animal models such as the tMCAO rat or mouse model readily mimic M1 occlusion in stroke patients and so far have been of great use understanding the pathophysiological process of ischemic brain injury and subsequent inflammation [35].

The chronological chain of events following brain ischemia comprises early neuronal death (within minutes) in the core infarct area, followed by a spreading of the infarct zone over a time course of the next hours, ongoing cell death in this particular region, and finally an edema formation which also strongly contributes to tissue damage [36-38]. Although there might exist distinct differences between human ischemic pathological sequela and those in rodent models, microglia and MDM activation typically begins as early as $2 \mathrm{~h}$ following the infarct onset and persists for one week or even longer [39]. Matching very well earlier findings, we have observed a pronounced microgliosis and MDM activation in the peri-infarct area at $72 \mathrm{~h}$ post-stroke in this study which is paralleled by a strong astrogliosis in our animal model [10, 11, 31, 33]. Immediately after ischemic stroke, activated microglia and MDMs release a set of pro-inflammatory cytokines, such as IL-1, IL-6, TNF- $\alpha$ and iNOS which all contribute to driving forward neuroinflammatory responses and finally to neuronal apoptosis [40]. Neuroinflammation caused by activated microglia and MDMs is considered as a critical factor of subsequent neurological functional deficits after stroke. The precise mechanisms of their activation following ischemia are not completely understood. It is also noteworthy, that local microglia and MDMs within the damaged area may also exhibit an anti- 
inflammatory phenotype and promote brain recovery by clearing cell debris and releasing antiinflammatory cytokines and trophic factors. Thus, the balance between these opposite cell activities appears critical in managing tissue and cell survival. According to these pivotal roles and their plasticity under pathophysiological conditions, microglia and MDMs are classified into "classically activated" M1 phenotype and the "alternatively activated" M2 phenotypes. Generally, the M1 phenotype possesses more cytotoxic functions by releasing pro-inflammatory factors which exacerbate brain infarction and damage [41]. In contrast, the M2 phenotype produces numerous protective and trophic factors such as TGF- $\beta$. The modulation of the balance between the pro- and anti-inflammatory phenotypes represents a novel and promising strategy for stroke treatment.

Estradiol has been demonstrated in the past to exert a neuroprotective and anti-inflammatory role in the CNS after acute pathological challenges including ischemic stroke [10, 11, 24, 31, 33, 42], spinal cord injury [16, 43], and traumatic brain injury [13, 44]. Interestingly, sex steroids are assumed to contribute or even account for well-described gender differences in the above listed acute brain injuries [45-48]. In previous animal studies and from the literature, it appears that, despite sex differences in general aspects of ischemic spreading and vulnerability, the protective effect of 17ß-estradiol is not limited to male or female were obvious gender difference in the responsiveness to estradiol observed [31]. We therefore assume, although not explicitly studied herein, that the observed effects of $17 ß$-estradiol on immune cell polarization does not reflect any gender specificity.

The polarization status of microglia and MDMs infiltrating the brain following ischemic injury is regulated and influenced by several factors and signaling mechanisms, among them also estrogens [18, 24, 49,50]. We have shown here in this study and in the past that estradiol significantly reduces the infarct volume and improves behavioral scoring [31]. One of our hypotheses was that estradiol reduces microglia and MDM numbers as well as activation status. Indeed, we observed a highly significant reduction in the numbers of leukocytes and in particular of activated microglia and MDMs after estradiol treatment in the ischemic cerebral cortex using a standardized novel ex vivo flow cytometry approach. For that, we had to optimize the experimental setting to remove myelin and debris. The methodological setting leads to the consequence that obtained cell numbers do not reflect absolute numbers but rather relative changes due to the treatment. Precisely, flow cytometry analysis revealed that estradiol attenuated the percentage of $\mathrm{CD} 45^{+}$cell numbers which at first glance indicate a reduction of local and infiltrated immune cells into the ischemic hemisphere. Using a setting with triple positive cells for CD45, CD11b and $\mathrm{CD} 11 \mathrm{c}$, the leukocyte cell population which was reduced in numbers was further characterized as 
microglia and MDMs. Following tissue injury, CD11b and CD11c are markers associated with infiltrating myeloid cells (monocyte-derived macrophages dendritic cells) as well as resident microglia, giving a mixed phenotype of various cells associated with the inflammation process. Accumulation of $\mathrm{CD}_{11 \mathrm{c}^{+}}$has been shown in several studies, arguing for a more mature, scavenging macrophage phenotype that is potentially also involved in the removal of cellular debris and therefore also in tissue regeneration in the course of brain injury regression [51-53]. Additional CD40 analysis showed that the reduced cell fraction mainly represents inflammatory activated microglia and MDMs. CD40 has been described mainly in the context of APC - T cell cross talk performed by dendritic cells and activated macrophages [54-57] and can be seen as a marker for robust, sustainable, inflammatory activation of the macrophage/dendritic cell population, the latter having also been described during the inflammatory phase of stroke associated leukocyte infiltration [58]. Time-course of gene expression in the peri-infarct zone of those markers used in the flow cytometry supports the above data and indicates that estradiol either prevents or mitigates the tMCAO-induced induction of marker genes, i.e. due to reduced microglia and MDM cell numbers, to cell-type specific expression levels or to a shift towards a M2 phenotype.

The biological effects of estradiol are mainly generated by binding and activation to its nERs. Besides classical nER being expressed in microglia [17, 59-61], GPR30, a seven transmembrane G protein-coupled receptor, is a mER which is highly expressed by microglia and significantly increased after ischemia [62]. This also applies to MDMs which contain a set of classical and nonclassical ERs and appear to be modulated by estradiol in their immune functions [63, 64]. GPR30 signals through the MAP kinase pathway or by adenylyl cyclase activation $[65,66]$. It has been shown that the activation of GPR30 significantly improved the neurological deficits and alleviated neuronal injuries after stroke [62].

There exists comprehensive information about the neuroprotective role of estradiol in the brain dating back to the mid-nineties of the last century [67]. In the early years of this millennium, the anti-inflammatory actions of estradiol in the brain was first described [68] and around the same time, it was suggested that neuroprotective estradiol effects are to a large extent based on the interaction with local microglia or invaded MDMs [69]. It is now evident that estradiol can activate GPR30, and this activation significantly may reduce TLR4 expression levels and NF- $\kappa$ B activity and finally influence microglial and MDM activation [62]. This might be one mechanism by which estradiol could shift microglia and MDMs from a M1 to M2 phenotype. In previous studies, we also demonstrated that estradiol suppresses the NLRP3 inflammasome activation and its associated production of IL-1 $\beta$ in the peri-infarct area after stroke [10]. This is of particular importance, since 
NLRP3-mediated signaling plays a pivotal role for cell damage during ischemic stroke [70]. Based on these findings it is possible that a decrease of NLPR3 inflammasome activation and its downstream cytokine IL-1 $\beta$ may be involved in facilitating the phenotype switch from M1 to M2 after estradiol treatment during ischemia [24, 71]. Clearly, inflammation is a multi-molecule cascade and hence, the possibility of the involvement of several pathways and different molecular switches is likely and requires further studies. We and others have recently observed that estradiol can regulate brain neuroprotective or pro-inflammatory microRNAs in general [72] and selectively in microglia [42]. microRNAs act as translational repressors which destabilize or degrade RNA transcripts and represent thus important regulatory elements in both tissue function and disease [73]. To give only one relevant example, estradiol induces MIR-375 expression which is implicated in the suppression of BCL2 and neuroinflammation in the brain [73]. In this context, our approach to isolate and analyze local microglia and MDMs in the peri-infarct brain by flow cytometry should be extended in the future by including single cell gene expression analysis. This would allow to associate the phenotype switches directly to the genomic activation and deactivation of genes and the expression of ERs.

In summary, our study shows that the early and continuing substitution of estradiol in male rats significantly dampens the activation of microglia and MDMs in the damaged cerebral cortex after tMCAO. This finding is supported by classical molecular and biochemical studies using selective gene markers for microglia and MDM activation which were reduced in their expression patterns. In addition, we applied a sophisticated novel approach using flow cytometry analysis with ex vivo tissue extracts which revealed concordant information with the molecular analyses. The latter method also delivers more accurate data about the subtype expression of leukocyte cell surface markers and will enable to picture a better chronological profile of changes of resident microglia and immigrated immune cells such as MDMs, T cells and B cells within the infarcted brain region in future. Since this study was performed on male rats only, it is difficult to speculate whether such regulatory protective effects by estradiol can also be seen in females. At least, an earlier study has shown that estradiol substitution in the IMCAO model is protective, anti-inflammatory and prevents microgliosis [31]. This makes it more likely that our observations may also apply to female rats. In favor for such an assumption are previously published data from our group concerning estradiol-dependent modulation of blood immune cell phenotypes and their activation status in adult human females [64]. This study describes a solid shift of macrophages and $T$ cell subpopulations to a more protective phenotype.

\section{Acknowledgements and Funding}


The kind help by Dr. A. Fragoulis is appreciated. This study was funded by the START program of the Medical Faculty of the RWTH Aachen University (A. Z.).

\section{Abbreviations}

BCL2 B-cell lymphoma 2

CCA Common carotid artery

CCL CC-chemokine ligand

CCR Chemokine receptor

CD Cluster of designation

CNS Central nervous system

CycloA Cyclophilin A

$\mathrm{CXCL} \quad$ Chemokine (C-X-C motif) ligand

DPBS Dulbecco's Phosphate-Buffered Saline

E/ estradiol 17ß-estradiol

ECA External carotid artery

FSC Forward scatter

FSC-W Forward scatter width

GPR30 G protein-coupled receptor 30 (mER)

HBSS Hank's Balanced Salt Solution

IBA-1 Ionized calcium-binding adapter molecule 1

ICA Internal carotid artery

IFN $\quad$ Interferon gamma

MDM(s) Monocyte derived macrophage(s)

mER Membrane-bound estrogen receptor

MFI Mean fluorescence intensity

MHC Major histocompatibility complex

M-MLV Murine leukemia virus reverse transcriptase

nER Nuclear estrogen receptor(s)

NLPR NOD-, LRR- and pyrin domain-containing protein

rCBF Regional cerebral blood flow

rcf Relative centrifugal force

SOD Superoxide dismutase

SSC Sideward Scatter 
tMCAO Transient middle cerebral artery occlusion

TTC 2,3,5-triphenyltetrazolium chloride

veh Vehicle

\section{Tables}

Table 1 Used primers and analyzed genes for RT-qPCR analysis.

\begin{tabular}{cllcc}
\hline Gene & & \multicolumn{1}{c}{ Sequence } & $\begin{array}{c}\text { Product } \\
\text { Size }\end{array}$ & $\begin{array}{c}\text { Annealing } \\
\text { Temperature }\end{array}$ \\
\hline \multirow{2}{*}{ CD45 } & s & CCGTTGTACACCAGAGATGA & $161 \mathrm{bp}$ & $62^{\circ} \mathrm{C}$ \\
& as & TCCCAAAATCAGTCTGCAC & & \\
CD11b & s & ACAGAGACCAAAGTGGAGCC & $162 \mathrm{bp}$ & $60^{\circ} \mathrm{C}$ \\
& as & GCCACCGGCTTCATTCATCA & & \\
CD40 & s & AGGTGGTCAAGAAACCAAAGGA & $105 \mathrm{bp}$ & $60^{\circ} \mathrm{C}$ \\
& as & CTGGAAGCAGCAGTGTTGTGA & & \\
CycloA & S & GGCAAATGCTGGACCAAACAC & $196 \mathrm{bp}$ & $65^{\circ} \mathrm{C}$ \\
& as & TTAGAGTTGTCCACAGTCGGAGATG & & \\
\hline
\end{tabular}

Table 2 Staining panel and antibody information.

\begin{tabular}{lll}
\hline Conjugated antibodies & Manufacturer & Order number \\
\hline CD32 & BD Biosciences & 550271 \\
CD45 (APC-Cy7) & Biolegend & 202216 \\
CD86 (PE) & BD Biosciences & 551396 \\
CD11b (APC) & BD Biosciences & 562102 \\
CD11c (FITC) & Biorbyt & ORB223665-50 \\
CD163 (PerCP) & AB online & ABIN4259472 \\
CD40 (eFluor450) & eBioscience & $48-0402-82$ \\
CD68 (PE-Cy7) & Miltenyi & $130-102-726$ \\
MHCII Biotin & Thermo Fisher & $13-0920-82$, \\
(Streptavidin-PE-TxRd) & & SA1017 \\
CCR2 (AlexaFluor700) & R\&D Systems & FAB8368N \\
\hline FVD506 & eBioscience & $65-0866-14$ \\
\hline
\end{tabular}




\section{Figures}

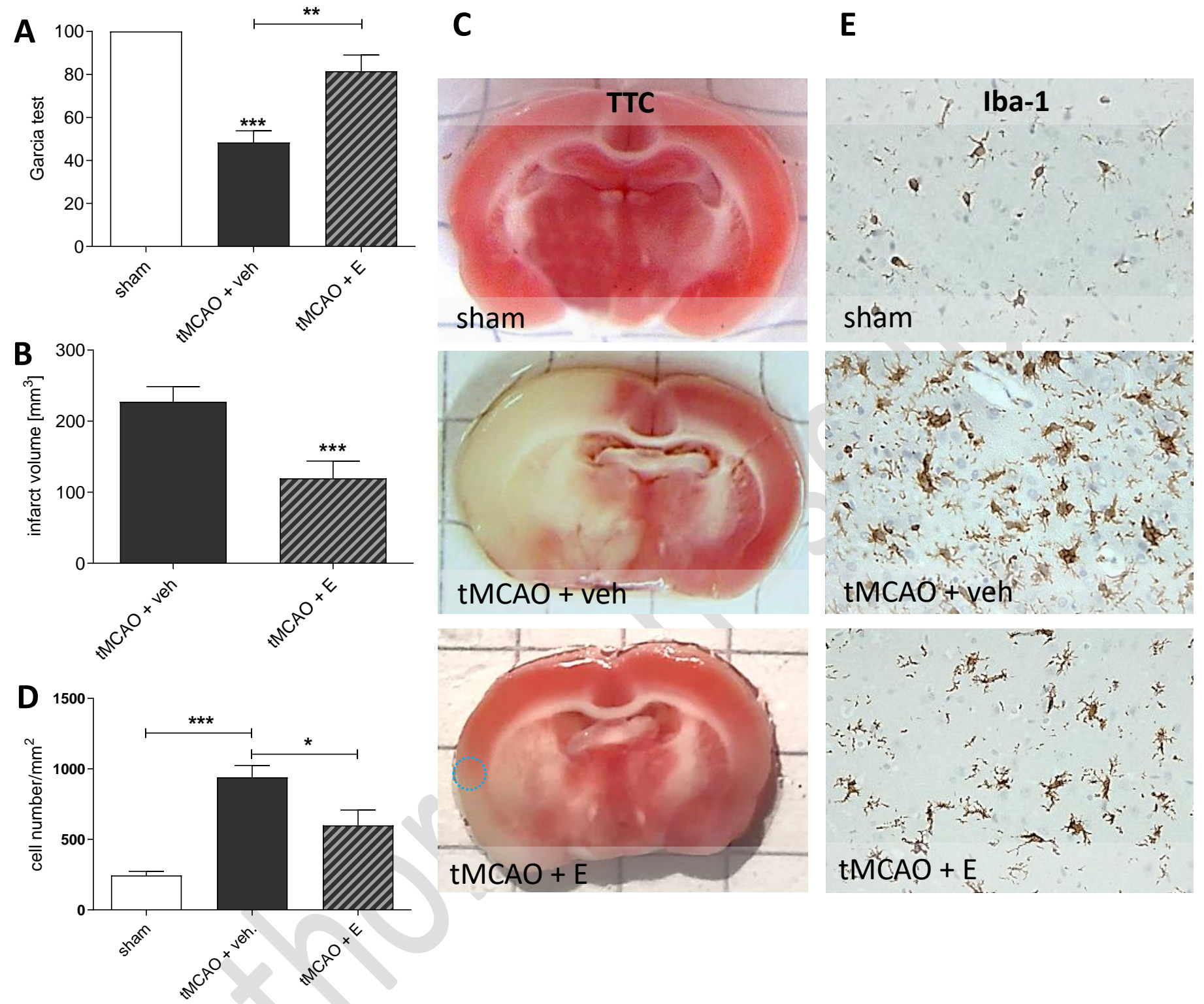

Figure 1

Evaluation of motor deficits, infarct volume and microglia/macrophage numbers after tMCAO followed by $72 \mathrm{~h}$ reperfusion and vehicle (veh) or estradiol ("E”) substitution compared to sham animals. (A) Garcia test scores (one-way ANOVA and Tukey's post hoc test), (B) cortical infarct volume (Student's t test), (C) Determination of the peri-infarct area (blue dotted circle) and representative pictures of TTC staining of brain slices, (D) Quantitative evaluation of the IBA-1 staining (one-way ANOVA and Tukey's post hoc test) and (E) representative pictures of IBA-1 staining of brain slices. ${ }^{*} p<0.05,{ }^{* *} p<0.005,{ }^{* *} p<0.001$, ns $=$ not significant. 


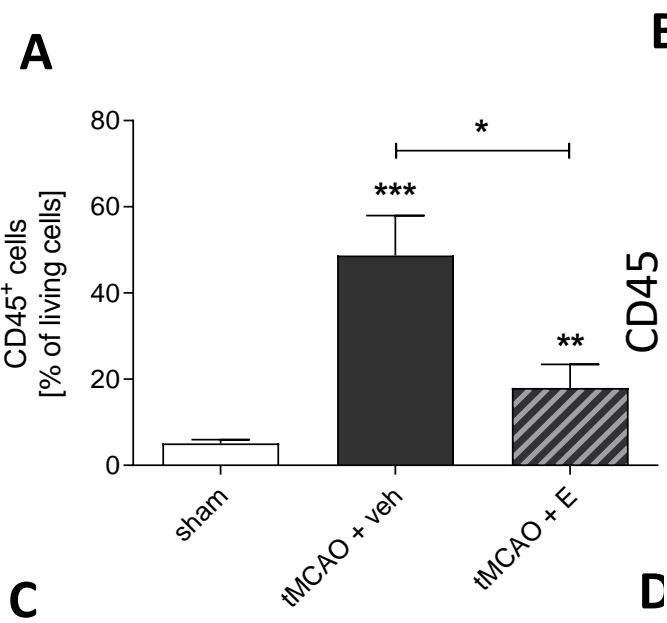

B
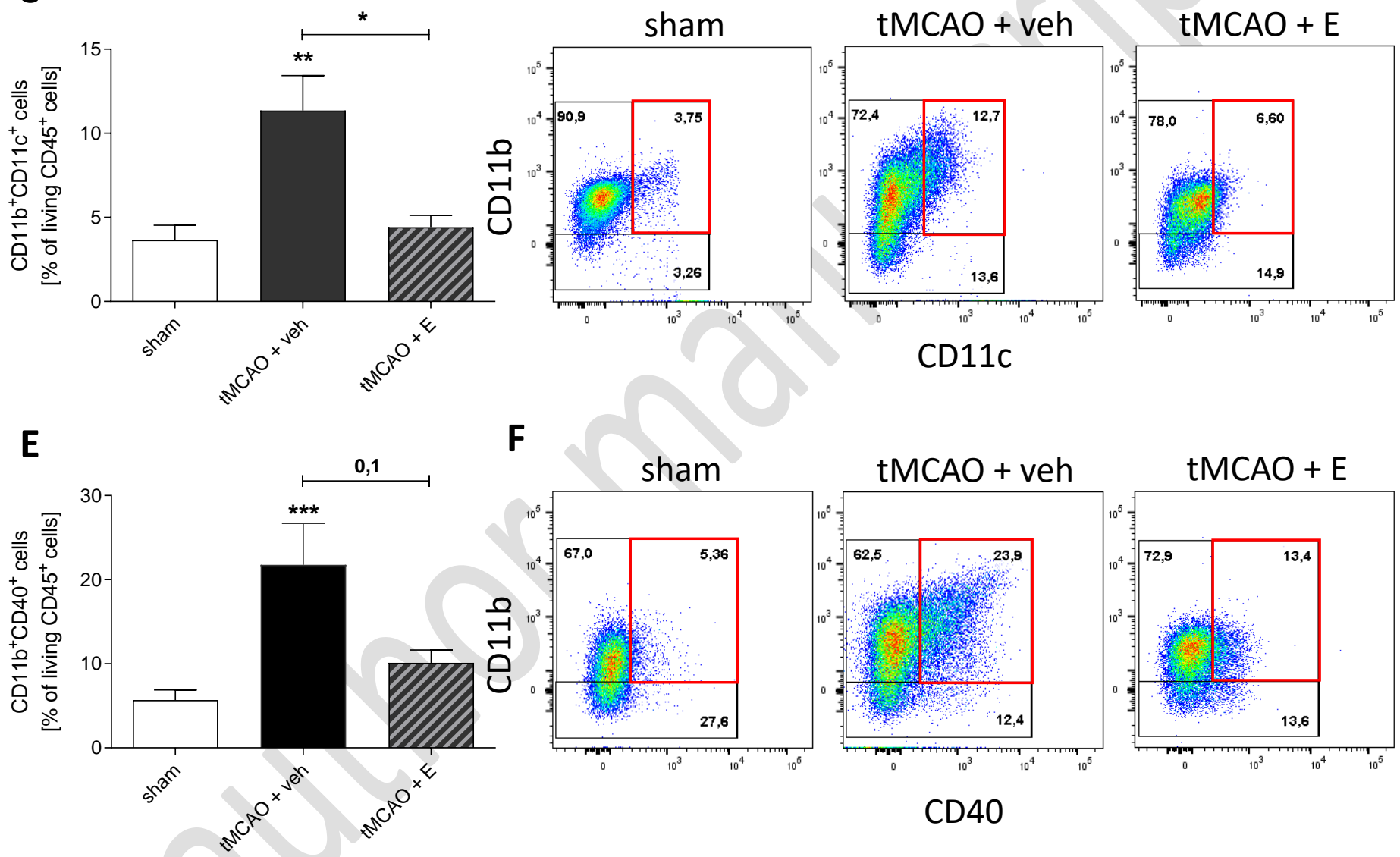

CD11c

FSC

Figure 2

Identification of the CD45 ${ }^{+}, C D 45^{+} \mathrm{CD} 11 \mathrm{~b}^{+} \mathrm{CD} 11 \mathrm{c}^{+}$and $\mathrm{CD} 45^{+} \mathrm{CD} 11 \mathrm{~b}^{+} \mathrm{CD} 40^{+}$cell populations by means of flow cytometry after tMCAO followed by $72 \mathrm{~h}$ reperfusion and estradiol substitution. (A), (C), (E) Evaluation of living $\mathrm{CD}_{4} 5^{+}, \mathrm{CD} 45^{+} \mathrm{CD} 11 \mathrm{~b}^{+} \mathrm{CD} 11 \mathrm{c}^{+}$and $\mathrm{CD} 45^{+} \mathrm{CD} 11 \mathrm{~b}^{+} \mathrm{CD} 40^{+}$cell percentages (one-way ANOVA and Tukey's post hoc test, Boxcox transformed). (B), (D), (F) Representative dot plots of CD45 versus FSC, CD11b versus $C D 11 \mathrm{c}$ and $C D 11 \mathrm{~b}$ versus $C D 40$ of sham and vehicle- or estradiol-treated tMCAO animals with the gate of interest (red box). ${ }^{*} \mathrm{p}<$ $0.05,{ }^{* *} p<0.005,{ }^{* * *} p<0.001$, ns $=$ not significant. 
A

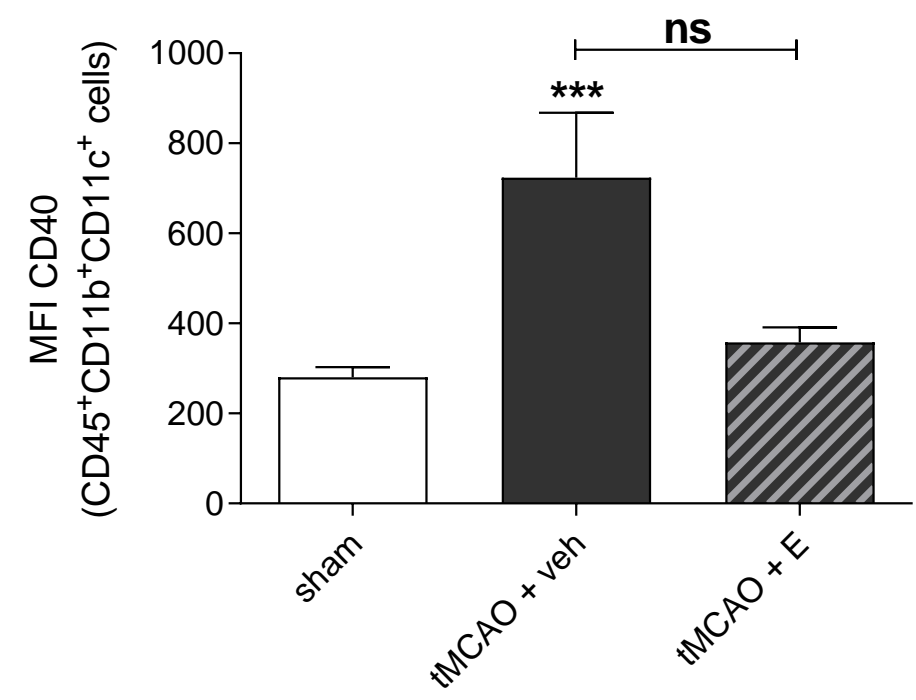

C CD11b

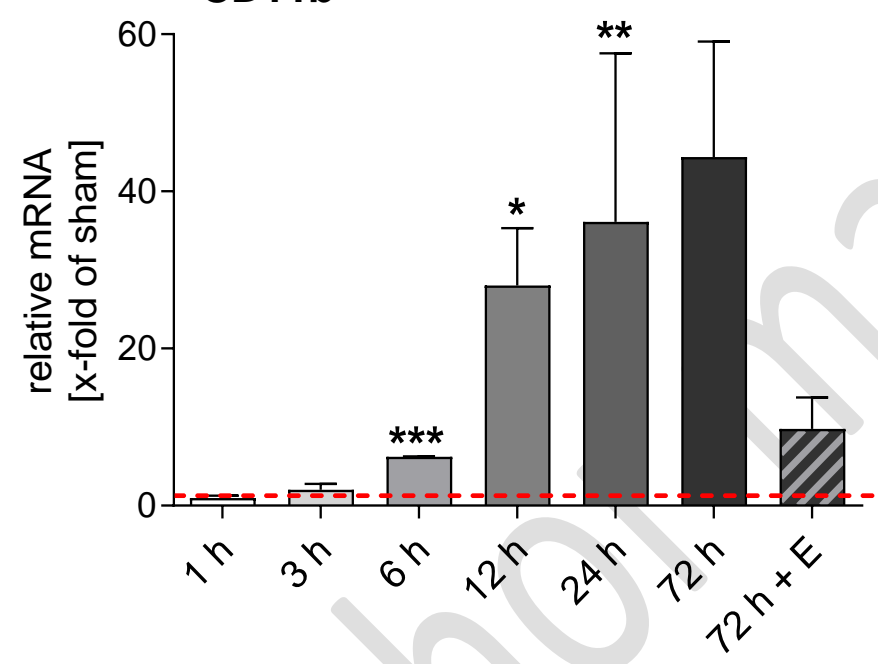

B CD45

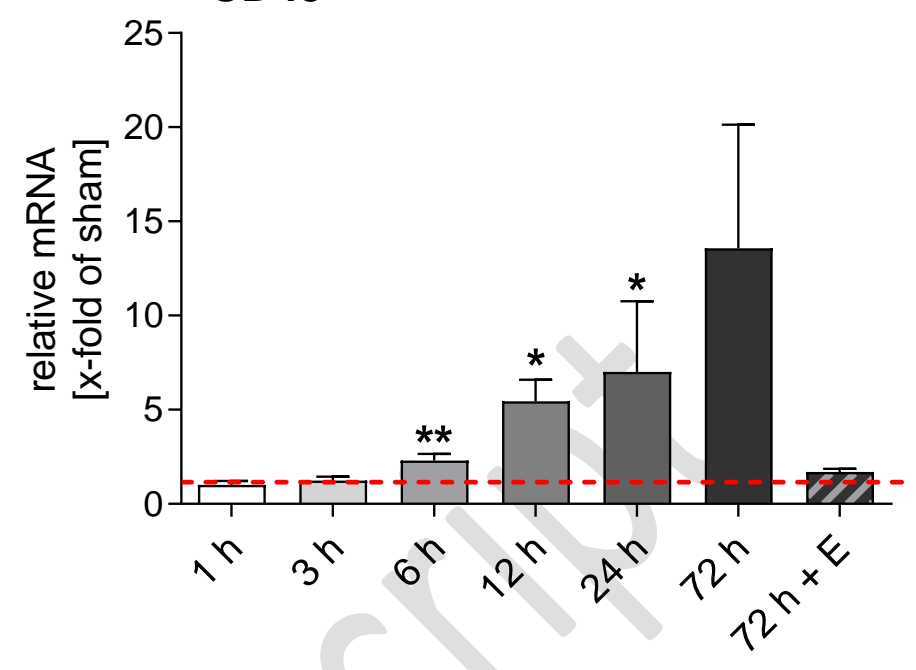

D CD40

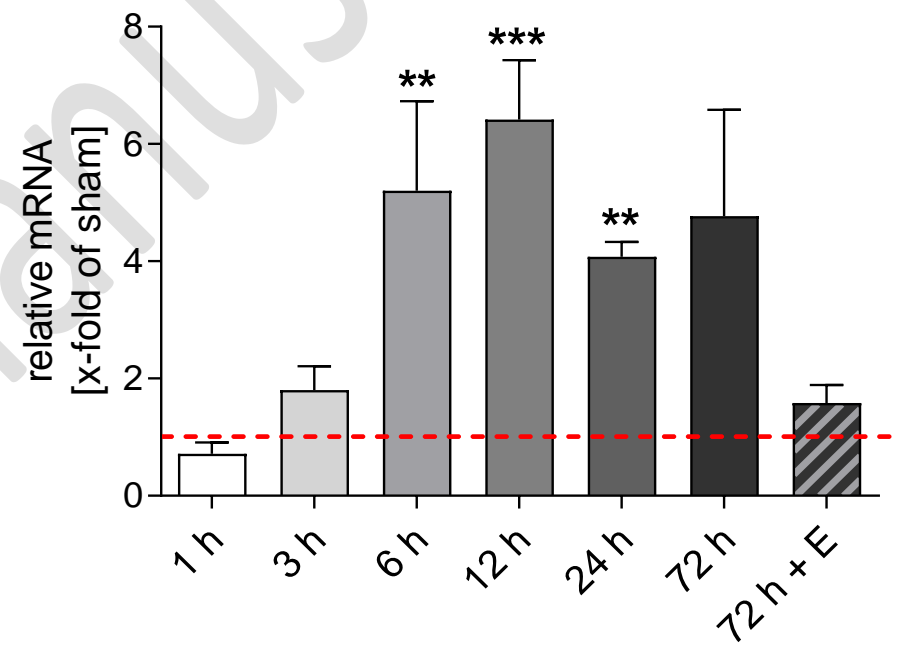

\section{Figure 3}

MFI of the activation marker CD40 and gene expression analysis of flow cytometry markers after tMCAO followed by $72 \mathrm{~h}$ reperfusion and estradiol substitution. (A) MFI of CD40 of the CD $45^{+} \mathrm{CD} 11 \mathrm{~b}^{+} \mathrm{CD} 11 \mathrm{c}^{+}$cell population (Kruskal-Wallis test and Dunn's multiple comparison test). (B) Relative mRNA of the peri-infarct brain tissue of CD45 (C) CD11b and (D) CD40 of sham (red dotted line), vehicle-treated tMCAO animals after 1, 3, 6, 12, 24 and $72 \mathrm{~h}$ of reperfusion and estradiol-treated tMCAO animals after $72 \mathrm{~h}$ of reperfusion (statistical analysis was performed with Student's $t$ test or Mann-Whitney test, in part Boxcox transformed, with analysis of tMCAO + veh versus sham and tMCAO + veh versus $\mathrm{tMCAO}+\mathrm{E}) .{ }^{*} \mathrm{p}<0.05,{ }^{* *} \mathrm{p}<0.005,{ }^{* * *} \mathrm{p}<0.001$, ns $=$ not significant. 
A

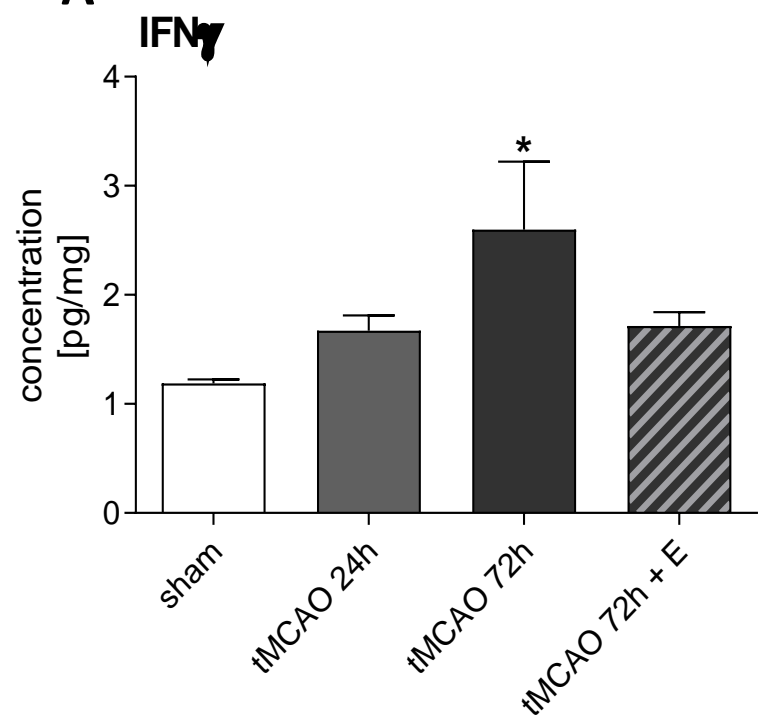

C

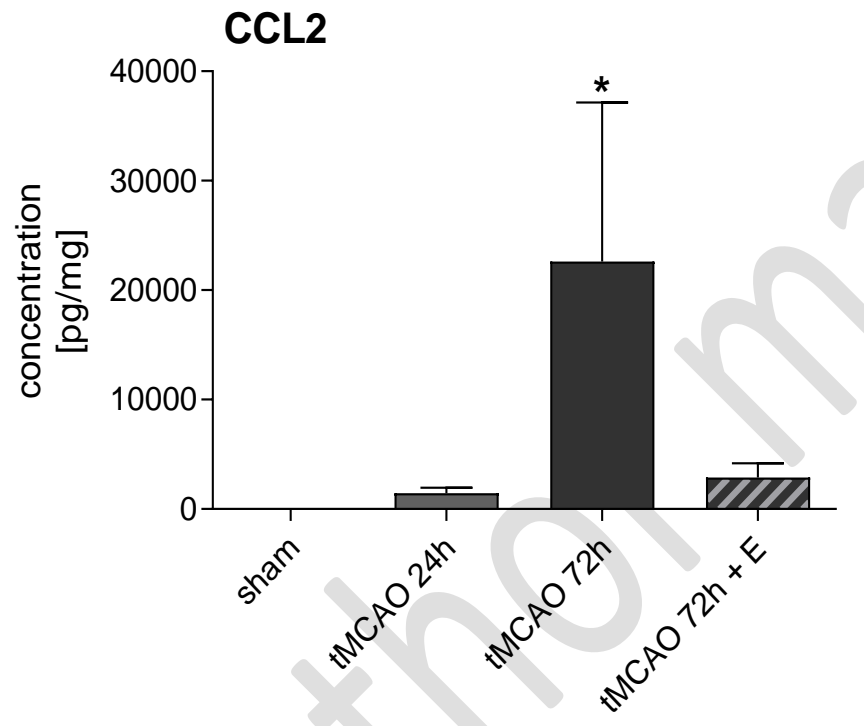

B

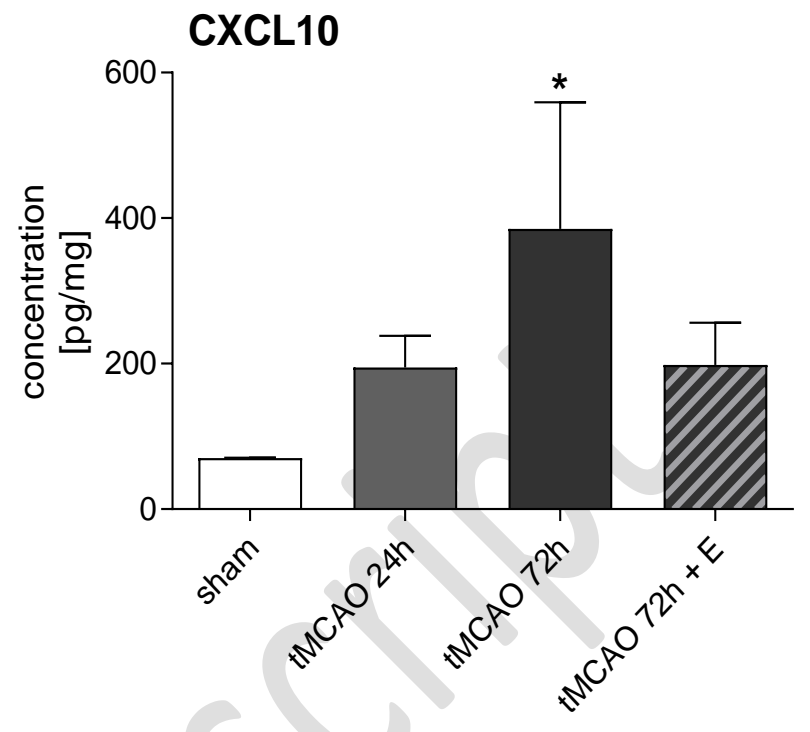

D

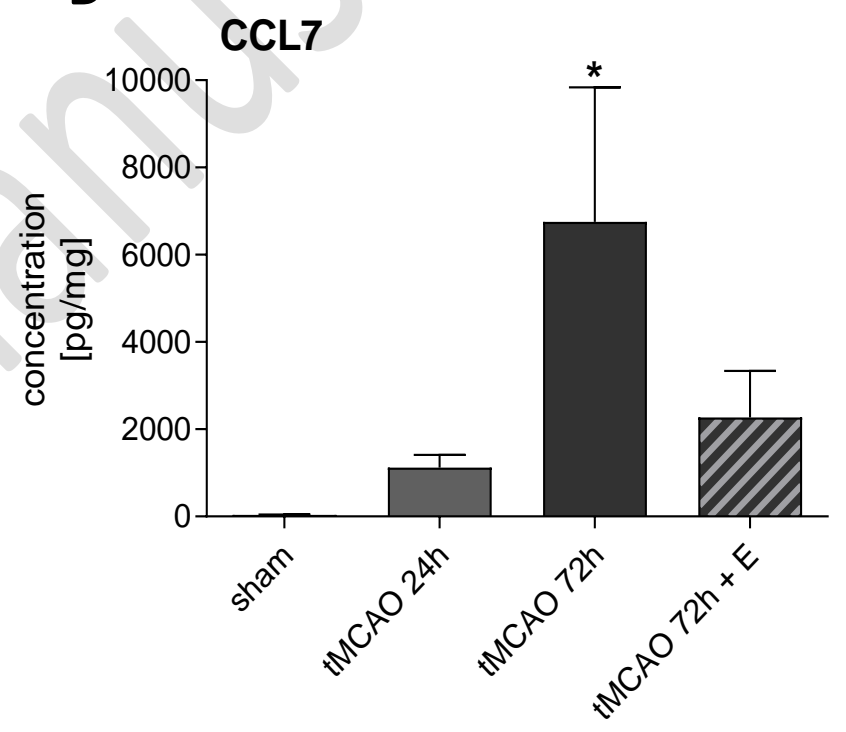

Figure 4

Protein concentrations of classical pro-inflammatory markers of peri-infarct area which were performed using multiplex analysis. (A) IFN $\gamma$ (one-way ANOVA and Tukey's post hoc test, Boxcox transformed), (B) CXCL10 (Kruskal-Wallis test and Dunn's multiple comparison test), (C) CCL2 (Kruskal-Wallis test and Dunn's multiple comparison test) and (D) CCL7 (Kruskal-Wallis test and Dunn's multiple comparison test) protein concentrations of sham, vehicle-treated animals after 24 and $72 \mathrm{~h}$ of reperfusion and estradiol-treated animals after $72 \mathrm{~h}$ of reperfusion. ${ }^{*} \mathrm{p}<0.05,{ }^{* *} \mathrm{p}<$ $0.005,{ }^{* *} p<0.001, \mathrm{~ns}=$ not significant. 
A

1h tMCAO

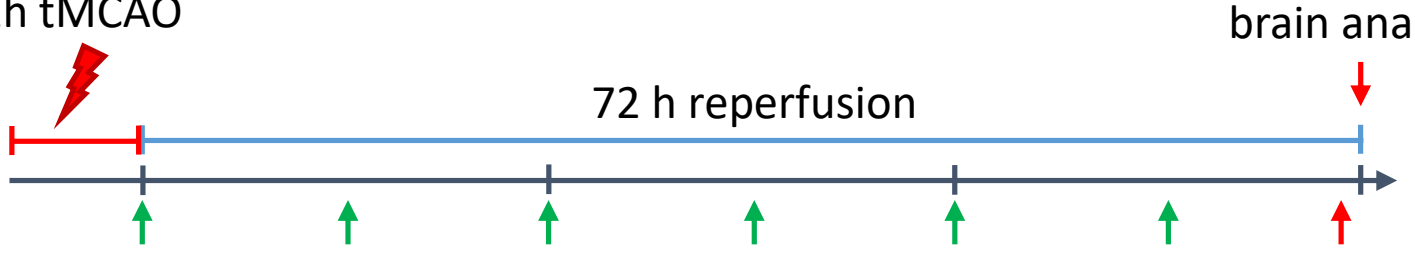

$17 \beta$-estradiol injection s.c. every $12 \mathrm{~h}$

motor tests

B

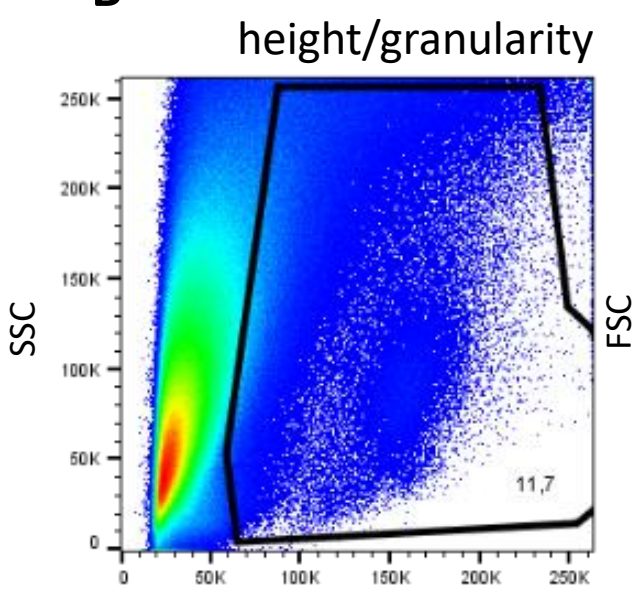

FSC

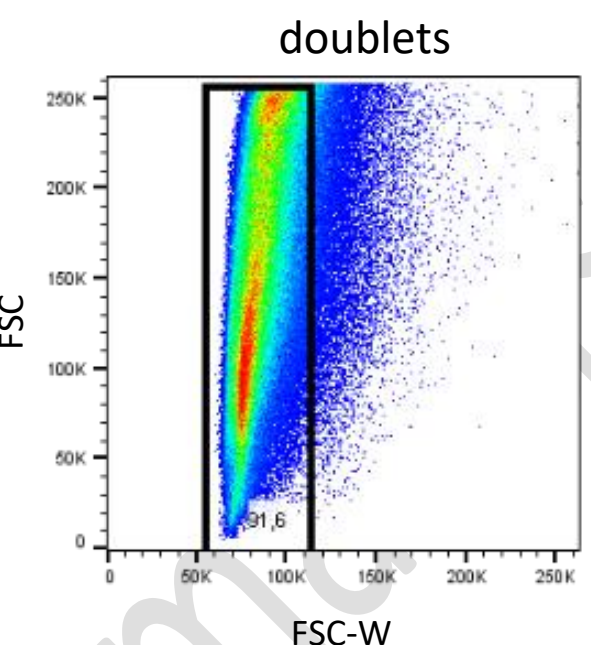

FSC-W

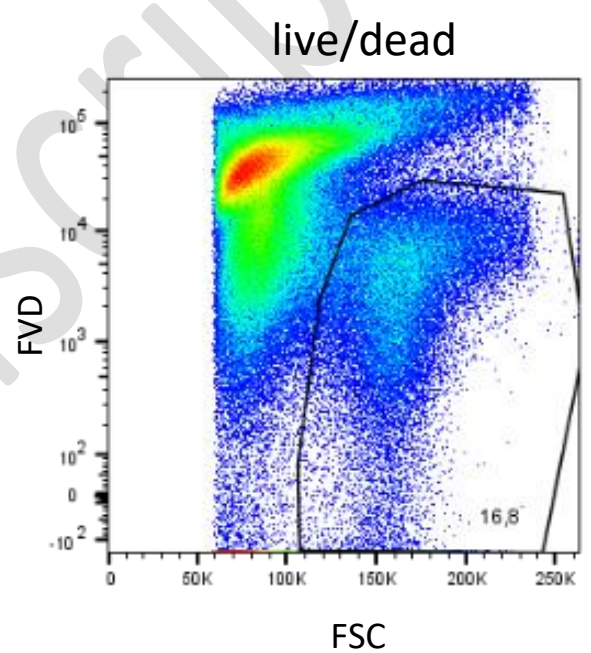

FSC

\section{Supplementary figure}

(A) Experimental setup and time scale of the tMCAO model and estradiol injections. (B) Gating strategy analyzing the height, granularity, width and living status of the cells with FlowJo v10.

\section{References}

1. Deroo BJ, Korach KS: Estrogen receptors and human disease. The Journal of clinical investigation 2006, 116(3):561-570.

2. O'Lone R, Frith MC, Karlsson EK, Hansen U: Genomic targets of nuclear estrogen receptors. Mol Endocrinol 2004, 18(8):1859-1875.

3. Beyer C, Pawlak J, Karolczak M: Membrane receptors for oestrogen in the brain. J Neurochem 2003, 87(3):545-550.

4. Saczko J, Michel O, Chwilkowska A, Sawicka E, Maczynska J, Kulbacka J: Estrogen Receptors in Cell Membranes: Regulation and Signaling. Adv Anat Embryol Cell Biol 2017, 227:93-105.

5. Levin ER: Plasma membrane estrogen receptors. Trends Endocrinol Metab 2009, 20(10):477-482.

6. Beyer C: Estrogen and the developing mammalian brain. Anatomy and embryology 1999, 199(5):379-390.

7. Taneja V: Sex Hormones Determine Immune Response. Frontiers in immunology 2018, 9:1931.

8. Roof RL, Hall ED: Gender differences in acute CNS trauma and stroke: neuroprotective effects of estrogen and progesterone. Journal of neurotrauma 2000, 17(5):367-388. 
9. Xu H, Gouras GK, Greenfield JP, Vincent B, Naslund J, Mazzarelli L, Fried G, Jovanovic JN, Seeger $M$, Relkin NR et al: Estrogen reduces neuronal generation of Alzheimer beta-amyloid peptides. Nature medicine 1998, 4(4):447-451.

10. Lammerding L, Slowik A, Johann S, Beyer C, Zendedel A: Poststroke Inflammasome Expression and Regulation in the Peri-Infarct Area by Gonadal Steroids after Transient Focal Ischemia in the Rat Brain. Neuroendocrinology 2016, 103(5):460-475.

11. Simpkins JW, Rajakumar G, Zhang YQ, Simpkins CE, Greenwald D, Yu CJ, Bodor N, Day AL: Estrogens may reduce mortality and ischemic damage caused by middle cerebral artery occlusion in the female rat. J Neurosurg 1997, 87(5):724-730.

12. De Nicola AF, Garay LI, Meyer M, Guennoun R, Sitruk-Ware R, Schumacher M, Gonzalez Deniselle MC: Neurosteroidogenesis and progesterone anti-inflammatory/neuroprotective effects. J Neuroendocrinol 2018, 30(2).

13. Brotfain E, Gruenbaum SE, Boyko M, Kutz R, Zlotnik A, Klein M: Neuroprotection by Estrogen and Progesterone in Traumatic Brain Injury and Spinal Cord Injury. Curr Neuropharmacol 2016, 14(6):641-653.

14. Azcoitia I, Barreto GE, Garcia-Segura LM: Molecular mechanisms and cellular events involved in the neuroprotective actions of estradiol. Analysis of sex differences. Front Neuroendocrinol 2019:100787.

15. Heitzer M, Kaiser S, Kanagaratnam M, Zendedel A, Hartmann P, Beyer C, Johann S: Administration of 17beta-Estradiol Improves Motoneuron Survival and Down-regulates Inflammasome Activation in Male SOD1(G93A) ALS Mice. Mol Neurobiol 2017, 54(10):8429-8443.

16. Zendedel A, Monnink F, Hassanzadeh G, Zaminy A, Ansar MM, Habib P, Slowik A, Kipp M, Beyer C: Estrogen Attenuates Local Inflammasome Expression and Activation after Spinal Cord Injury. Mol Neurobiol 2018, 55(2):1364-1375.

17. Kipp M, Hochstrasser T, Schmitz C, Beyer C: Female sex steroids and glia cells: Impact on multiple sclerosis lesion formation and fine tuning of the local neurodegenerative cellular network. Neurosci Biobehav Rev 2016, 67:125-136.

18. Habib P, Beyer C: Regulation of brain microglia by female gonadal steroids. J Steroid Biochem Mol Biol 2015, 146:3-14.

19. Kolominsky-Rabas PL, Heuschmann PU: Fortschr Neurol Psychiatr, vol. 70(12): Georg Thieme; 2002.

20. Nour M, Scalzo F, Liebeskind DS: Ischemia-reperfusion injury in stroke. Interventional neurology 2013, 1(3-4):185-199.

21. Kawabori M, Yenari MA: Inflammatory responses in brain ischemia. Current medicinal chemistry 2015, 22(10):1258-1277.

22. Chamorro A, Meisel A, Planas AM, Urra X, van de Beek D, Veltkamp R: The immunology of acute stroke. Nature reviews Neurology 2012, 8(7):401-410.

23. Bruce-Keller AJ, Keeling JL, Keller JN, Huang FF, Camondola S, Mattson MP: Antiinflammatory effects of estrogen on microglial activation. Endocrinology 2000, 141(10):3646-3656.

24. Thakkar R, Wang R, Wang J, Vadlamudi RK, Brann DW: 17beta-Estradiol Regulates Microglia Activation and Polarization in the Hippocampus Following Global Cerebral Ischemia. Oxid Med Cell Longev 2018, 2018:4248526.

25. Pelekanou V, Kampa M, Kiagiadaki F, Deli A, Theodoropoulos P, Agrogiannis G, Patsouris E, Tsapis $A$, Castanas $E$, Notas $G$ : Estrogen anti-inflammatory activity on human monocytes is mediated through cross-talk between estrogen receptor ERalpha36 and GPR30/GPER1. Journal of leukocyte biology 2016, 99(2):333-347.

26. Mor G, Nilsen J, Horvath T, Bechmann I, Brown S, Garcia-Segura LM, Naftolin F: Estrogen and microglia: A regulatory system that affects the brain. Journal of neurobiology 1999, 40(4):484496. 
27. Ghisletti S, Meda C, Maggi A, Vegeto E: 17beta-estradiol inhibits inflammatory gene expression by controlling NF-kappaB intracellular localization. Molecular and cellular biology 2005, 25(8):2957-2968.

28. Ranjbar Taklimie F, Gasterich N, Scheld M, Weiskirchen R: Hypoxia Induces Astrocyte-Derived Lipocalin-2 in Ischemic Stroke. 2019, 20(6).

29. Zendedel A, Habib P, Dang J, Lammerding L, Hoffmann S, Beyer C, Slowik A: Omega-3 polyunsaturated fatty acids ameliorate neuroinflammation and mitigate ischemic stroke damage through interactions with astrocytes and microglia. Journal of neuroimmunology 2015, 278:200-211.

30. Garcia JH, Wagner S, Liu KF, Hu XJ: Neurological deficit and extent of neuronal necrosis attributable to middle cerebral artery occlusion in rats. Statistical validation. Stroke 1995, 26(4):627-634; discussion 635.

31. Dang J, Mitkari B, Kipp M, Beyer C: Gonadal steroids prevent cell damage and stimulate behavioral recovery after transient middle cerebral artery occlusion in male and female rats. Brain Behav Immun 2011, 25(4):715-726.

32. Zendedel A, Johann S, Mehrabi S, Joghataei MT, Hassanzadeh G, Kipp M, Beyer C: Activation and Regulation of NLRP3 Inflammasome by Intrathecal Application of SDF-1a in a Spinal Cord Injury Model. Mol Neurobiol 2016, 53(5):3063-3075.

33. Ulbrich C, Zendedel A, Habib P, Kipp M, Beyer C, Dang J: Long-term cerebral cortex protection and behavioral stabilization by gonadal steroid hormones after transient focal hypoxia. J Steroid Biochem Mol Biol 2012, 131(1-2):10-16.

34. Liu F, McCullough LD: Middle cerebral artery occlusion model in rodents: methods and potential pitfalls. Journal of biomedicine \& biotechnology 2011, 2011:464701.

35. Durukan A, Tatlisumak T: Acute ischemic stroke: overview of major experimental rodent models, pathophysiology, and therapy of focal cerebral ischemia. Pharmacology, biochemistry, and behavior 2007, 87(1):179-197.

36. Sharp FR, Jickling GC, Stamova B, Tian Y, Zhan X, Liu D, Kuczynski B, Cox CD, Ander BP: Molecular markers and mechanisms of stroke: RNA studies of blood in animals and humans. $J$ Cereb Blood Flow Metab 2011, 31(7):1513-1531.

37. Yang SH, Shetty RA, Liu R, Sumien N, Heinrich KR, Rutledge M, Thangthaeng N, Brun-Zinkernagel $A M$, Forster MJ: Endovascular middle cerebral artery occlusion in rats as a model for studying vascular dementia. Age (Dordr) 2006, 28(3):297-307.

38. Bigdeli MR, Asheghabadi $M$, Khalili A: Time course of neuroprotection induced by normobaric hyperoxia in focal cerebral ischemia. Neurol Res 2012, 34(5):439-446.

39. Zhang RL, Chopp M, Zaloga C, Zhang ZG, Jiang N, Gautam SC, Tang WX, Tsang W, Anderson DC, Manning AM: The temporal profiles of ICAM-1 protein and mRNA expression after transient MCA occlusion in the rat. Brain research 1995, 682(1-2):182-188.

40. Lambertsen KL, Biber K, Finsen B: Inflammatory cytokines in experimental and human stroke. Journal of cerebral blood flow and metabolism : official journal of the International Society of Cerebral Blood Flow and Metabolism 2012, 32(9):1677-1698.

41. Gregersen R, Lambertsen K, Finsen B: Microglia and macrophages are the major source of tumor necrosis factor in permanent middle cerebral artery occlusion in mice. Journal of cerebral blood flow and metabolism : official journal of the International Society of Cerebral Blood Flow and Metabolism 2000, 20(1):53-65.

42. Herzog R, Zendedel A, Lammerding L, Beyer C, Slowik A: Impact of 17beta-estradiol and progesterone on inflammatory and apoptotic microRNA expression after ischemia in a rat model. The Journal of steroid biochemistry and molecular biology 2017, 167:126-134. 
43. Li XM, Yang Q, Li XB, Cheng Q, Zhang K, Han J, Zhao JN, Liu G, Zhao MG: Estrogen-like neuroprotection of isopsoralen against spinal cord injury through estrogen receptor ERalpha. Metab Brain Dis 2017, 32(1):259-265.

44. Chakrabarti M, Das A, Samantaray S, Smith JA, Banik NL, Haque A, Ray SK: Molecular mechanisms of estrogen for neuroprotection in spinal cord injury and traumatic brain injury. Rev Neurosci 2016, 27(3):271-281.

45. Kim T, Chelluboina B, Chokkalla AK, Vemuganti R: Age and sex differences in the pathophysiology of acute CNS injury. Neurochem Int 2019, 127:22-28.

46. Spani CB, Braun DJ, Van Eldik LJ: Sex-related responses after traumatic brain injury: Considerations for preclinical modeling. Front Neuroendocrinol 2018, 50:52-66.

47. Golz C, Kirchhoff FP, Westerhorstmann J, Schmidt M, Hirnet T, Rune GM, Bender RA, Schafer MKE: Sex hormones modulate pathogenic processes in experimental traumatic brain injury. $J$ Neurochem 2019, 150(2):173-187.

48. Kaidonis G, Rao AN, Ouyang YB, Stary CM: Elucidating sex differences in response to cerebral ischemia: immunoregulatory mechanisms and the role of microRNAs. Prog Neurobiol 2019, 176:73-85.

49. Yuan Y, Wu C, Ling EA: Heterogeneity of Microglia Phenotypes: Developmental, Functional and Some Therapeutic Considerations. Curr Pharm Des 2019, 25(21):2375-2393.

50. Pan MX, Tang JC, Liu R, Feng YG, Wan Q: Effects of estrogen receptor GPR30 agonist G1 on neuronal apoptosis and microglia polarization in traumatic brain injury rats. Chin J Traumatol 2018, 21(4):224-228.

51. Wlodarczyk A, Lobner M, Cedile O, Owens T: Comparison of microglia and infiltrating CD11c(+) cells as antigen presenting cells for $T$ cell proliferation and cytokine response. J Neuroinflammation 2014, 11:57.

52. Sato-Hashimoto M, Nozu T, Toriba R, Horikoshi A, Akaike M, Kawamoto K, Hirose A, Hayashi $Y$, Nagai $\mathrm{H}$, Shimizu $\mathrm{W}$ et al: Microglial SIRPalpha regulates the emergence of CD11c(+) microglia and demyelination damage in white matter. Elife 2019, 8.

53. Kamphuis W, Kooijman L, Schetters S, Orre M, Hol EM: Transcriptional profiling of CD11c-positive microglia accumulating around amyloid plaques in a mouse model for Alzheimer's disease. Biochim Biophys Acta 2016, 1862(10):1847-1860.

54. Benveniste EN, Nguyen VT, Wesemann DR: Molecular regulation of CD40 gene expression in macrophages and microglia. Brain Behav Immun 2004, 18(1):7-12.

55. Nguyen VT, Benveniste EN: Involvement of STAT-1 and ets family members in interferon-gamma induction of CD40 transcription in microglia/macrophages. J Biol Chem 2000, 275(31):2367423684.

56. D'Aversa TG, Weidenheim KM, Berman JW: CD40-CD40L interactions induce chemokine expression by human microglia: implications for human immunodeficiency virus encephalitis and multiple sclerosis. Am J Pathol 2002, 160(2):559-567.

57. Becher B, Durell BG, Miga AV, Hickey WF, Noelle RJ: The clinical course of experimental autoimmune encephalomyelitis and inflammation is controlled by the expression of CD40 within the central nervous system. J Exp Med 2001, 193(8):967-974.

58. Felger JC, Abe T, Kaunzner UW, Gottfried-Blackmore A, Gal-Toth J, McEwen BS, ladecola C, Bulloch $\mathrm{K}$ : Brain dendritic cells in ischemic stroke: time course, activation state, and origin. Brain Behav Immun 2010, 24(5):724-737.

59. Pozzi S, Benedusi V, Maggi A, Vegeto E: Estrogen action in neuroprotection and brain inflammation. Ann N Y Acad Sci 2006, 1089:302-323.

60. Arevalo MA, Diz-Chaves Y, Santos-Galindo M, Bellini MJ, Garcia-Segura LM: Selective oestrogen receptor modulators decrease the inflammatory response of glial cells. J Neuroendocrinol 2012, 24(1):183-190. 
61. Johann S, Beyer C: Neuroprotection by gonadal steroid hormones in acute brain damage requires cooperation with astroglia and microglia. J Steroid Biochem Mol Biol 2013, 137:71-81.

62. Zhang Z, Qin P, Deng Y, Ma Z, Guo H, Guo H, Hou Y, Wang S, Zou W, Sun Y et al: The novel estrogenic receptor GPR30 alleviates ischemic injury by inhibiting TLR4-mediated microglial inflammation. Journal of neuroinflammation 2018, 15(1):206.

63. Holtman IR, Skola D, Glass CK: Transcriptional control of microglia phenotypes in health and disease. J Clin Invest 2017, 127(9):3220-3229.

64. Habib P, Dreymueller D, Rosing B, Botung H, Slowik A, Zendedel A, Habib S, Hoffmann S, Beyer C: Estrogen serum concentration affects blood immune cell composition and polarization in human females under controlled ovarian stimulation. J Steroid Biochem Mol Biol 2018, 178:340-347.

65. Filardo EJ, Quinn JA, Bland KI, Frackelton AR, Jr.: Estrogen-induced activation of Erk-1 and Erk-2 requires the $G$ protein-coupled receptor homolog, GPR30, and occurs via trans-activation of the epidermal growth factor receptor through release of HB-EGF. Mol Endocrinol 2000, 14(10):16491660.

66. Filardo EJ, Quinn JA, Frackelton AR, Jr., Bland KI: Estrogen action via the G protein-coupled receptor, GPR30: stimulation of adenylyl cyclase and CAMP-mediated attenuation of the epidermal growth factor receptor-to-MAPK signaling axis. Mol Endocrinol 2002, 16(1):70-84.

67. Singer CA, Rogers KL, Strickland TM, Dorsa DM: Estrogen protects primary cortical neurons from glutamate toxicity. Neurosci Lett 1996, 212(1):13-16.

68. Ciesielska A: [Immunosuppressive aspects of estrogen]. Neurol Neurochir Pol 2003, 37 Suppl 3:7992.

69. Vegeto E, Belcredito S, Ghisletti S, Meda C, Etteri S, Maggi A: The endogenous estrogen status regulates microglia reactivity in animal models of neuroinflammation. Endocrinology 2006, 147(5):2263-2272.

70. Luo Y, Reis C, Chen S: NLRP3 Inflammasome in the Pathophysiology of Hemorrhagic Stroke: A Review. Curr Neuropharmacol 2019, 17(7):582-589.

71. Thakkar R, Wang R, Sareddy G, Wang J, Thiruvaiyaru D, Vadlamudi R, Zhang Q, Brann D: NLRP3 Inflammasome Activation in the Brain after Global Cerebral Ischemia and Regulation by 17betaEstradiol. Oxid Med Cell Longev 2016, 2016:8309031.

72. He J, Gao Y, Wu G, Lei X, Zhang Y, Pan W, Yu H: Molecular mechanism of estrogen-mediated neuroprotection in the relief of brain ischemic injury. BMC Genet 2018, 19(1):46.

73. Kloosterman WP, Plasterk RH: The diverse functions of microRNAs in animal development and disease. Developmental cell 2006, 11(4):441-450. 